\title{
On the Prediction of Clusters for Adverse Reactions and Allergies on Antibiotics for Children to Improve Biomedical Decision Making
}

\author{
Pinar Yildirim ${ }^{1}$, Ljiljana Majnarić $^{2}$, Ozgur Ilyas Ekmekci ${ }^{1}$, and Andreas Holzinger ${ }^{3}$ \\ ${ }^{1}$ Department of Computer Engineering, Faculty of Engineering \& Architecture, \\ Okan University, Istanbul, Turkey \\ \{pinar.yildirim, oekmekci\} @okan.edu.tr \\ ${ }^{2}$ School of Medicine, University J.J. Strossmayer Osijek, 31 000, \\ Osijek, Croatia \\ ljiljana.majnaric@it.t-com.hr \\ ${ }^{3}$ Institute for Medical Informatics, Statistics \& Documentation \\ Medical University Graz, A-8036 Graz, Austria \\ andreas.holzinger@medunigraz .at
}

\begin{abstract}
In this paper, we report on a study to discover hidden patterns in survey results on adverse reactions and allergy (ARA) on antibiotics for children. Antibiotics are the most commonly prescribed drugs in children and most likely to be associated with adverse reactions. Record on adverse reactions and allergy from antibiotics considerably affect the prescription choices. We consider this a biomedical decision problem and explore hidden knowledge in survey results on data extracted from the health records of children, from the Health Center of Osijek, Eastern Croatia. We apply the K-means algorithm to the data in order to generate clusters and evaluate the results. As a result, some antibiotics form their own clusters. Consequently, medical professionals can investigate these clusters, thus gaining useful knowledge and insight into this data for their clinical studies.
\end{abstract}

Keywords: Adverse reactions and allergy (ARA), knowledge discovery, biomedical data mining, k-means algorithm.

\section{Introduction}

Antibiotics are the drugs most commonly prescribed to children and are most likely to be associated with allergic and adverse reactions [1],[2],[3],[4]. A reaction to a drug is considered an allergic reaction if it involves an immunologic reaction to a drug. It may occur in the form of immediate or non-immediate (delayed) hypersensitivity reactions. Immediate reactions are usually mediated with $\mathrm{IgE}$ antibodies (often elevated in persons with inherited susceptibility to allergic diseases, called atopy), whereas non-immediate reactions can be mediated with several other immune mechanisms [5]. The clinical manifestations of antibiotic allergy include skin reactions (varying from local and mild general to severe general reactions), 
organ-specific reactions (most commonly occuring in the form of blood dyscrasias, hepatitis and interstitial nephritis) and systemic reactions (usually corresponding with anaphylaxis) [5]. Many reactions to drugs mimic symptoms and signs of the allergic reactions, although being caused with non-immunologic mechanisms. In many cases, also, pathologic mechanisms remain completely unclear. This is the reason why these reactions are often considered together and commonly named adverse reactions and allergy (ARA) [6]. This term is especially appropriate for use in primary health care setting, where patients who had experienced ARA on antibiotics have rarely been referred to testing. Moreover, diagnostic tests are limited and are only standardized for penicillin allergy [6].

Antibiotic classes with higher historical use have been shown to have higher allergy prevalence [7]. Published papers on frequency, risk factors and preventability of this medical problem in the general population, and especially in children, are scarce. Available data implicate female sex, frequent use, older age, insufficient prescribing strategy and monitoring of prescribed medications, as the primary factors accounting for higher prevalence of ARA on antibiotics among adults. Similar data for children are completely absent [8].

The aim of this study is to explore hidden knowledge in the survey data extracted from health records on adverse reactions and allergy on antibiotics in children in the town of Osijek, Eastern Croatia. We plan to obtain some serious and useful information in electronic health records that are not easily recognized by researchers, clinicians and pharmaceutical companies.

\section{Related Work}

There have been several studies performed for knowledge discovery on drug adverse events associations. Kadoyama et al. searched the FDA's AERS (Adverse Event Reporting System) and carried out a study to confirm whether the database could suggest the hypersensitivity reactions caused by anticancer agents, paclitaxel, docetaxel, procarbazine, asparaginase, teniposide and etoposide. They used some data mining algorithms, such as proportional reporting ratio (PRR), the reporting odds ratio(ROR) and the empirical Bayes geometric mean (EBGM) to identify drugassociated adverse events and consequently, they detected some associations [9].

Tsymbal et al. investigated antibiotics resistance data and proposed a new ensemble machine learning technique, where a set of models are built over different time periods and the best model is selected. They analyzed the data collected from N.N. Burdenko Institute of Neurosurgery in Russia and the dataset consisted of some features such as: patient and hospitalization related information, pathogen and pathogen groups and antibiotics and antibiotic groups. Their experiments with the data show that dynamic integration of classifiers built over small time intervals can be more effective than the best single learning algorithm applied in combination with feature selection, which gives the best known accuracy for the considered problem domain [10]. 
Lamma et al. described the application of data mining techniques in order to automatically discover association rules from microbiological data and obtain alarm rules for data validation. Their dataset consists of information about the patient such as sex, age, hospital unit, the kind of material (specimen) to be analyzed (e.g., blood, urine, saliva, pus, etc.), bacterium and its antibiogram. They applied the Apriori algorithm to the dataset and developed some interesting rules [11].

\section{Methods}

\section{The Study Population and Data Sources}

The study was done on the population of 1491 children (769 children of the school age, 7-18 years old, the rest of the preschool age), all patients in the same Health Center in the town of Osijek, Eastern Croatia, cared for by a family physician and a primary pediatrician teams.

Data were extracted from the health records of these children. Knowledge of risk factors for ARA on antibiotics in children are scarce. In making a choice for data collection, a co-author physician used personal knowledge on factors influencing the immunologic reactions together with information from the studies on risk factors for allergic diseases in children [12],[13],[14],[15],[16],[17],[18],[19]. Data extraction, from the patients health records, was guided by a multi-item chart, in an advance prepared by this co-author. In addition, parents of children recorded on ARA on antibiotics were interviewed by telephone, on a family history of ARA on antibiotics and other allergic and chronic diseases, in which pathogenesis, in a great part, immunologic mechanisms are involved. Data were summarized.

Registered information on ARA on antibiotics was found in health records of 46 children, out of a total of 1491 children screened, implicating the overall prevalence of ARA on antibiotics of 3,15\%. However, higher prevalence was found in children of the school age $(4,9 \%)$, then in those of the preschool age $(1,1 \%)$, data probably reflecting the cummulative incidence rates with age. When the incidence data were however estimated, it has been shown that ARA on antibiotics, in our study population, can be expected to occur predominantely in preschool age (33/46 cases, 71,1\%).

Of registered ARA events, almost all were mild-moderate skin reactions. Only one case was in need for hospitalization (a18-year-old girl, treated with the combination of amoxicillin and clavulonic acid). All data, including descriptions of ARA events (upon which classification of severity reaction was made) and diagnoses of diseases, were based on the native physicians` records.

\section{Clustering Analysis by k-means Algorithm}

Cluster analysis is one of the main data analysis method in data mining research.The process of grouping a set of physical or abstract objects into classes of similar objects is called clustering. A cluster is a collection of data objects that are similar to one another and are dissimilar to the objects in other clusters. Cluster analysis has been widely used in numerous applications, including pattern recognition, data analysis, image processing and biomedical research. 
In this study, we use k-means algorithm to survey results on adverse reactions and allergy (ARA) on antibiotics in children. The k-means algorithm is a type of partitioning algorithm and is simple and effective. The k-means algorithm is widely used due to easy implementaion and fast execution. The algorithm takes the input parameter, $k$, and partitions a set of $n$ objects into $\mathrm{k}$ clusters so that the resulting intracluster similarity is high but inter-cluster similarity is low. Cluster similarity is measured with regard to the mean value of the objects in a cluster, which can be viewed as the cluster's center of gravity. The pseudo code of a k-means algorithm is as follows:

1. arbitrarily choose $k$ objects as the initial cluster centers

2. repeat

3. (re)assign each object to the cluster to which the object is the most similar, based on the mean value of the objects in the cluster

4. update the cluster means, i.e., calculate the mean value of the objects for each cluster

5. until no change.

The distance from the mean values of the objects in the clusters are calculated by using distance measures. The Euclidean distance is one of the common distance measures and is defined as the square root of the squared discrepancies between two entities summed over all variables (i.e., features) measured. For any two entities A and $\mathrm{B}$ and $\mathrm{k}=2$ features, say $\mathrm{X} 1$ and $\mathrm{X} 2, d_{a b}$ is the length of the hypotenuse of a right triangle. The square of the distance between the points representing $\mathrm{A}$ and $\mathrm{B}$ is obtained as follows:

$$
d_{a b}=\left[\left(\mathrm{X}_{\mathrm{a} 1}-\mathrm{X}_{\mathrm{b} 1}\right)^{2}+\left(\mathrm{X}_{\mathrm{a} 2}-\mathrm{X}_{\mathrm{b} 2}\right)^{2}\right]^{1 / 2}[20]
$$

\section{$4 \quad$ Experimental Results}

We selected samples from the survey results and created a dataset. Table 1 lists the antibiotics used in the dataset. The dataset consists of 26 attributes and 42 instances (Table 2 and Table 3). The k-means algorithm was used to explore some hidden clusters in the dataset. WEKA 3.6.8 software was used. WEKA is a collection of machine learning algorithms for data mining tasks and is an open source software. The software contains tools for data pre-processing, classification, regression, clustering, association rules and visualization [21], [22].

K-means algorithm requires the number of clusters $(k)$ in the data to be pre-specified. Finding the appropriate number of clusters for a given dataset is generally a trial and error process made more difficult by the subjective nature of deciding what 'correct' clustering. The performance of a clustering algorithm may be affected by the chosen value of $k$. Reported studies on k-means clustering and its applications usually do not contain any explanation or justification for selecting particular values for $k$ [23]. 
Table 1. Type of antibiotics used in survey

\section{Type of antibiotics}

\begin{tabular}{cc}
\hline $\begin{array}{c}\text { Short name used in the dataset } \\
\text { ampicilin } \\
\text { cef\& pen } \\
\text { pen\&klav } \\
\text { klav } \\
\text { azitrom } \\
\text { cef } \\
\text { fenoksi } \\
\text { cefalosporins \& penicillin } \\
\text { cefuroks } \\
\text { penicillin \& amoxicillin+clavulanic acid } \\
\text { amoxicillin+clavulanic acid - a broad-spectrum } \\
\text { azithromycin - a macrolide group } \\
\text { cefalosporins - a broad-spectrum } \\
\text { sulfa } \\
\text { eritrom } \\
\text { cenoksimetil penicillin - per os penicillin, a narrow- } \\
\text { spectrum }\end{array}$ \\
\end{tabular}

The k-means algorithm implementation in many data-mining or data analysis software packages requires the number of clusters to be specified by the user. To find a satisfactory clustering result, usually, a number of iterations are needed where the user executes the algorithm with different values of $k$ [23]. In order to evaluate the performance of simple k-means algorithm in our study, two test modes were used, training set and percentage split (holdout method). The training set refers to a widely used experimental testing procedure where the database is randomly divided into $\mathrm{k}$ disjoint blocks of objects, then the data mining algorithm is trained using k-1 blocks and the remaining block is used to test the performance of the algorithm, this process is repeated $\mathrm{k}$ times. At the end, the recorded measures are averaged. It is common to choose $\mathrm{k}=10$ or any other size depending mainly on the size of the original dataset.

In percentage split (holdout method), the database is randomly split into two disjoint datasets. The first set, which the data mining system tries to extract knowledge from called training set. The extracted knowledge may be tested against the second set which is called test set, it is common to randomly split a dataset under the mining task into 2 parts and has $66 \%$ of the objects of the original database as a training set and the rest of objects as a test set. Once the tests were carried out using our dataset, results were collected and an overall comparison was conducted [24]. 
Table 2. The attributes used in the dataset (1-17)

\begin{tabular}{|c|c|c|c|}
\hline No & Attribute & Description & Type \\
\hline 1 & Age & The patient's age & Numeric \\
\hline 2 & Age of ARA & $\begin{array}{l}\text { Age when the allergic/adverse } \\
\text { reaction on antibiotics occurred }\end{array}$ & Numeric \\
\hline 3 & Type of antibiotic & $\begin{array}{c}\text { Generic name of the antibiotic } \\
\text { by which the allergic reaction } \\
\text { was provoked }\end{array}$ & Nominal \\
\hline 4 & Severity reaction & $\begin{array}{l}\text { The clinically graded } \\
\text { allergic/adverse reaction }\end{array}$ & Ordinal \\
\hline 5 & $\begin{array}{l}\text { Age of the 1st } \\
\text { antibiotic use (y) }\end{array}$ & $\begin{array}{c}\text { Age when the first antibiotic } \\
\text { was used }\end{array}$ & Numeric \\
\hline 6 & $\begin{array}{l}\text { Other allergic } \\
\text { disease (skin) }\end{array}$ & $\begin{array}{c}\text { Does a child have some other } \\
\text { allergic disease? (manifestation } \\
\text { on the skin) }\end{array}$ & Nominal (Yes, No) \\
\hline 7 & $\begin{array}{c}\text { Other allergic } \\
\text { disease ( rhinitis) }\end{array}$ & $\begin{array}{l}\text { Does a child have some other } \\
\text { allergic disease? (in the form of } \\
\text { allergic rhinitis) }\end{array}$ & Nominal (Yes, No) \\
\hline 8 & $\begin{array}{l}\text { Other allergic } \\
\text { disease } \\
\text { (bronchitis) }\end{array}$ & $\begin{array}{l}\text { Does a child have some other } \\
\text { allergic disease? (in the form of } \\
\text { obstructive bronchitis) }\end{array}$ & Nominal (Yes, No) \\
\hline 9 & $\begin{array}{c}\text { Other allergic } \\
\text { disease (asthma) }\end{array}$ & $\begin{array}{l}\text { Does a child have some other } \\
\text { allergic disease? (in the form of } \\
\text { asthma) }\end{array}$ & Nominal (Yes, No) \\
\hline 10 & $\begin{array}{l}\text { Blood test on } \\
\text { allergy - IgE }\end{array}$ & $\begin{array}{c}\text { Have the antibodies of the } \mathrm{IgE} \\
\text { type (which usually raise in } \\
\text { allergic diseases) been } \\
\text { measured? }\end{array}$ & $\begin{array}{c}\text { Nominal (Positive, } \\
\text { Negative) }\end{array}$ \\
\hline 11 & Perinatal disorders & $\begin{array}{l}\text { Disorders occurring during } \\
\text { delivery and the first hours } \\
\text { after the birth }\end{array}$ & Nominal (Yes, No) \\
\hline 12 & $\begin{array}{l}\text { The child birth } \\
\text { order }\end{array}$ & $\begin{array}{l}\text { Born as the first, or the second, } \\
\text { etc., child in order }\end{array}$ & Ordinal \\
\hline 13 & $\begin{array}{l}\text { Severe respiratory } \\
\text { disease }\end{array}$ & $\begin{array}{l}\text { A respiratory disease which is } \\
\text { severe enough to be a life } \\
\text { frightening (e.g. laryngitis, } \\
\text { pneumonia) }\end{array}$ & Nominal (Yes, No) \\
\hline 14 & $\begin{array}{l}\text { Age of severe } \\
\text { respiratory disease }\end{array}$ & $\begin{array}{l}\text { Age when some type of severe } \\
\text { respiratory disease occurred }\end{array}$ & Numeric \\
\hline 15 & Otits media & Otits media & Nominal (Yes, No) \\
\hline 16 & $\begin{array}{l}\text { Age of otitis } \\
\text { media }\end{array}$ & $\begin{array}{l}\text { Age when otitis media } \\
\text { occurred }\end{array}$ & Numeric \\
\hline 17 & Other infections & $\begin{array}{l}\text { Had there been some other } \\
\text { infection before the } \\
\text { allergic/adverse reaction on } \\
\text { antibiotics occured? }\end{array}$ & Nominal (Yes, No) \\
\hline
\end{tabular}


Table 3. The attributes used in the dataset (18-26)

\begin{tabular}{|c|c|c|c|}
\hline No & Attribute & Description & Type \\
\hline 18 & $\begin{array}{l}\text { Other infections } \\
\text { (the number of } \\
\text { episodes) }\end{array}$ & $\begin{array}{l}\text { How many episodes of } \\
\text { infections had there been } \\
\text { before the allergic/adverse } \\
\text { reaction on antibiotics } \\
\text { occurred? }\end{array}$ & Nominal \\
\hline 19 & Varicella & $\begin{array}{c}\text { Did the varicella infection } \\
\text { occur? }\end{array}$ & Nominal (Yes, No) \\
\hline 20 & Age of varicella & $\begin{array}{c}\text { Age when varicella infection } \\
\text { occurred }\end{array}$ & Numeric \\
\hline 21 & $\begin{array}{l}\text { Hospitalization } \\
<2 \mathrm{y} \text { of age }\end{array}$ & $\begin{array}{l}\text { Hospitalization in the very } \\
\text { early childhood }\end{array}$ & Nominal (Yes, No) \\
\hline 22 & $\begin{array}{c}\text { Number of } \\
\text { infections per year }\end{array}$ & $\begin{array}{l}\text { An average number of } \\
\text { infections per year in a } \\
\text { particular child, } \\
\text { independently on when the } \\
\text { allergic/adverse reaction on } \\
\text { antibiotics occurred }\end{array}$ & Numeric \\
\hline 23 & $\begin{array}{c}\text { Antibiotic } \\
\text { exposure before } \\
\text { ARA }\end{array}$ & $\begin{array}{l}\text { How many times antibiotics } \\
\text { had been prescribed before } \\
\text { the allergic/ adverse reaction } \\
\text { on antibiotics occurred? }\end{array}$ & Ordinal \\
\hline 24 & $\begin{array}{c}\text { Family history on } \\
\text { ARA }\end{array}$ & $\begin{array}{l}\text { Family history on } \\
\text { allergic/adverse reactions on } \\
\text { antibiotics }\end{array}$ & $\begin{array}{c}\text { Nominal(Positive, } \\
\text { Negative) }\end{array}$ \\
\hline 25 & $\begin{array}{l}\text { Allergic diseases } \\
\text { in family }\end{array}$ & $\begin{array}{l}\text { Have there been other } \\
\text { allergic diseases in family } \\
\text { members? }\end{array}$ & Nominal(Yes, No) \\
\hline 26 & $\begin{array}{c}\text { Chr diseases } \\
\text { diseases in family }\end{array}$ & $\begin{array}{l}\text { Have there been other } \\
\text { chronic diseases in family } \\
\text { members? }\end{array}$ & Nominal (Yes, No) \\
\hline
\end{tabular}

Table 4. Evaluation of cluster analysis with training set mode

\begin{tabular}{cccc}
\hline K value & $\begin{array}{c}\text { Number of } \\
\text { iterations }\end{array}$ & $\begin{array}{c}\text { Within cluster sum of } \\
\text { squared errors }\end{array}$ & Runtime(Seconds) \\
\hline 2 & 3 & 459.114 & 0.01 \\
3 & 4 & 444.553 & 0.01 \\
4 & 3 & 430.279 & 0.01 \\
5 & 5 & 415.160 & 0.01 \\
\hline
\end{tabular}




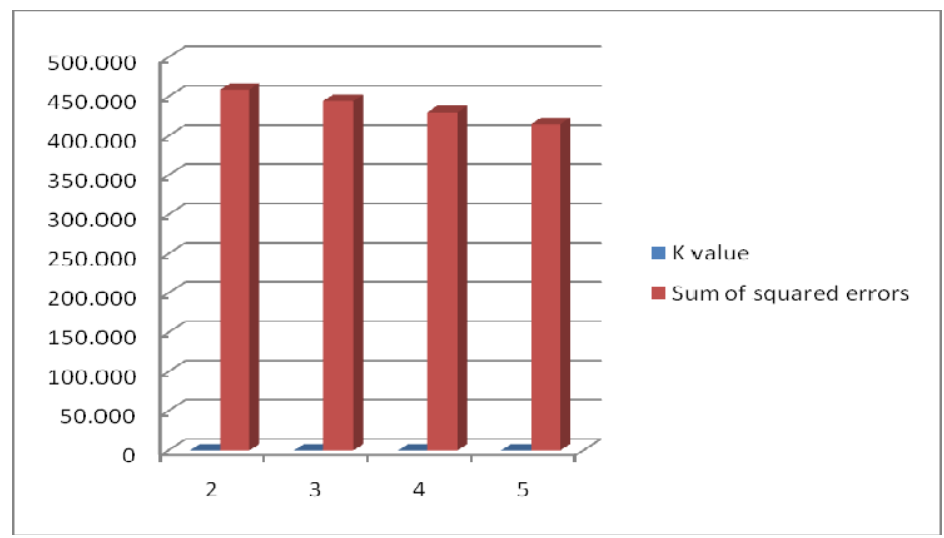

Fig. 1. Sum of squared errors and $\mathrm{k}$ values with training set mode

Table 5. Evaluation of cluster analysis with percentage split test set mode

\begin{tabular}{ccrc}
\hline K value & $\begin{array}{c}\text { Number of } \\
\text { iterations }\end{array}$ & $\begin{array}{c}\text { Within cluster sum of } \\
\text { squared errors }\end{array}$ & Runtime(Seconds) \\
\hline 2 & 3 & $459.114(66 \%)$ & 0 \\
& 3 & $293.226(34 \%)$ & 0.01 \\
3 & 4 & $444.553(66 \%)$ & 0.01 \\
& 5 & $279.846(34 \%)$ & \multirow{2}{*}{0.01} \\
& 3 & $430.279(66 \%)$ & \\
\hline
\end{tabular}

We also tried different number of clusters $(2<=k<=5)$ for each test mode and we observed the results of number of iterations, sum of squared errors and runtime. Sum of squared error (SSE) is an evaluation measure that determines how closely related are objects in a cluster. The formula of SSE is as follows:

$$
\mathrm{SSE}=\sum_{i} \sum_{x \in C i} d i s t^{2}\left(x, m_{i}\right)
$$

$C_{i}$ is the $j$ th cluster, $m_{i}=$ centroid of cluster $C_{i}$ (the mean vector of all the data points in $\left.C_{j}\right)$, and $\operatorname{dist}\left(\mathbf{x}, \mathbf{m}_{j}\right)$ is the distance between data point $\mathbf{x}$ and centroid $\mathbf{m}_{j}[25]$.

The results after analysis are described in Table 4 and 5. We compared the results of the number of clusters obtained by simple k-means algorithm and we found that greater number of clusters produced smaller sum of squared errors. For example, when $\mathrm{k}$ value is 2 which is default in Weka, sum of squared error is 459.114 , on the other hand, when $\mathrm{k}$ value increased to 4 , new value of sum of squared error is 430.279(Fig 1). Table 6 shows clusters with training set mode and with $\mathrm{k}=4$. 
Table 6. Clusters obtained by k-means algorithm with training set mode and $\mathrm{k}=4$

\section{$\begin{array}{llll}\text { Attribute } & \text { Cluster1 Cluster2 Cluster3 Cluster4 }\end{array}$}

\begin{tabular}{|c|c|c|c|c|}
\hline Age & 14.5 & 14.0 & 16.0 & 16.0 \\
\hline Age of ARA & 5.0 & 6.0 & 0.4 & $<1$ \\
\hline $\begin{array}{l}\text { Type of antibiotic } \\
\text { Severity reaction }\end{array}$ & $\begin{array}{l}\text { cef\&pen } \\
\text { skin }\end{array}$ & $\begin{array}{l}\text { pen } \\
\text { skin }\end{array}$ & $\begin{array}{l}\text { fenoksi } \\
\text { skin }\end{array}$ & $\begin{array}{l}\text { ampicilin } \\
\text { skin }\end{array}$ \\
\hline $\begin{array}{c}\text { Age of the 1st antibiotic } \\
\text { use (y) }\end{array}$ & 5.0 & $<1$ & $<1$ & $<1$ \\
\hline $\begin{array}{l}\text { Other allergic disease } \\
\text { (skin) }\end{array}$ & yes & no & no & yes \\
\hline $\begin{array}{l}\text { Other allergic disease } \\
\text { (rhinitis) }\end{array}$ & no & no & no & no \\
\hline $\begin{array}{l}\text { Other allergic disease } \\
\text { (bronchitis) }\end{array}$ & no & no & no & yes \\
\hline $\begin{array}{l}\text { Other allergic disease } \\
\text { (asthma) }\end{array}$ & no & no & no & no \\
\hline Blood test on allergy - IgE & positive & positive & positive & positive \\
\hline Perinatal disorders & yes & no & no & yes \\
\hline Birth order & 1 & 1.379 & 1.2828 & 1.2685 \\
\hline Severe respiratory disease & yes & no & no & Yes \\
\hline $\begin{array}{c}\text { Age of severe respiratoy } \\
\text { disease }\end{array}$ & 1.5 & 6.0 & 6.0 & 6.0 \\
\hline Otitis media & yes & yes & no & Yes \\
\hline Age of otitis media & 9.0 & $<1$ & $<1$ & $<1$ \\
\hline Other infections & yes & yes & yes & Yes \\
\hline $\begin{array}{l}\text { Other infections } \\
\text { (the number of episodes) }\end{array}$ & $1 \mathrm{X}$ & $2 \mathrm{X}$ & $2 X$ & $2 \mathrm{X}$ \\
\hline Varicella & yes & no & yes & no \\
\hline Age of varicella & 7.5 & 3.0 & 3.0 & 3.0 \\
\hline Hospitalization $<2$ y of age & no & no & no & no \\
\hline $\begin{array}{c}\text { Number of infections per } \\
\text { year }\end{array}$ & $3-4 X$ & $2-3 X$ & $2-3 X$ & $3 \mathrm{X}$ \\
\hline $\begin{array}{c}\text { Antibiotic exposure } \\
\text { before ARA }\end{array}$ & $2 \mathrm{X}$ & $1 \mathrm{X}$ & $1 \mathrm{X}$ & $1 \mathrm{X}$ \\
\hline Family history on ARA & negative & negative & negative & positive \\
\hline Allergic diseases in family & no & no & no & no \\
\hline $\begin{array}{c}\text { Chr diseases diseases in } \\
\text { family }\end{array}$ & no & no & no & no \\
\hline
\end{tabular}

The results of the k-means algorithm revealed some patterns in the survey data and four clusters were generated (Table 6). According to the results, some types of antibiotics form their own clusters such as cef\&pen, pen, fenoksi and ampicilin. 
Medical researchers and clinicians can consider and explore these patterns to create some medical ideas.

\section{Discussion}

This is a collaborative study of an interdisciplinary team, composed of informaticians and a physician (a GP). The role of a physician was in forming a research question and data collection and in providing comments on health-related issues.

An overall frequency of ARA on antibiotics of 3,15\% was observed. Rarely available data for the paediatric population indicates the overall incidence of $9,35 \%$ in hospitalized children and $1,46 \%$ in outpatients [26]. Many factors can affect the variation in the frequency of this disorder, including the children age (as shown in our paper), the natural distribution of risk factors in the population, the types of antibiotics prescribed, the custom of ARA recording and physicians' education on both, symptoms and mechanisms of ARA and antibiotic prescription [27].

When all four clusters in parallel were put into consideration, some general rules, in regard to ARA in children, coud be observed. As the first, there were two time peaks of the ARA occurrence: in the year of birth and in the late pre-school age (around 5-6 y). In older children with ARA, the causing antibiotics were classified as with higher historical use (penicillin).

Some common characteristics of children with ARA might include: 1) predisposition to allergic disorders (positive $\operatorname{IgE}$ blood test), 2) however, not manifested with allergic respiratory diseases (hay fever and asthma). This connection should be taken into account even if it is known that allergic diseases show the timedependent occurrence during the childhood (the so-called "allergic march", manifested as a progression of atopic diseases from eczema to asthma), for reason that the current age of cases with ARA corresponds with adolescence (14-16 year). These results seem contrary to what is known from the early studies, that atopic subjects do not show higher incidence of penicillin allergy, in comparison to the general population [6]. It cannot, in fact, be known, from our results, whether atopy in children can also increase their predisposition for ARA on drugs (especially on antibiotics other than penicillin), or whether, on the contrary, early antibiotic exposure increases the risk for atopic diseases, as postulated traditionally [13]. Or, these results may be only due to the confounding effects, consequently to the predominant use of $\beta$-lactam antibiotics in children. Namely, undesirable reactions on these antibiotics are known as being predominantly caused by allergic mechanisms, usually mediated with IgE antibodies [6]. Nevertheless, these results can direct future prevention strategies, mainly by means of preserved prescriptions of antibiotics in children with increased $\operatorname{IgE}$ antibodies.

Other constant and common features of children with ARA include: 3) at least one episode of infections (other than respiratory infections, also including otitis media) experienced before the time of ARA occurrence, as well as an early antibiotic use (in the first year of life). These results might be reflective of the immune system disturbation, in the early childhood, which can increase the chance for both, ARA on antibiotics and infections. Also, there are information that some infections can serve 
as a promoting factor, by ensuring conditions for the immune reaction on a drug to start, which otherwise could not be the case [5]. In addition to these explanations, the second result might also implicate the increased risk for ARA to occur, through the negative effect of an early antibiotic use on the commensal intestinal flora and the subsequent impairments of the immune system development [17], [18].

Some additional factors, found to commonly occur in children with ARA, include: 4) frequent infections (defined as two or more times per year), reflecting poor hygiene, or the immune system dysfunction, and 5) low antibiotic pre-exposure counts (1-2 times), indicating sensitizing reaction as the possible mechanism of ARA. In accordance to the latter, it is commonly known that patients usually develop allergic reactions when reexposed to an antibiotic [6].

When clusters 3 and 4, representing an early onset of ARA (during the first year of life), were compared to each other, somewhat different patterns were obtained, probably indicating different mechanisms between ARA on ampicilin (a broadspectrum antibiotic) and fenoksimetilpenicilin (a narrow-spectrum penicillin for an oral use). Otherwise, these antibiotics share the common structure, that of the $\beta$ lactam antibiotic group, also sharing some common features [5].

In regard to ampicilin, other allergic diseases, including skin eczema and obstructive bronchitis (both disorders occurring early along the course of the "allergic march"), may contribute to the onset of ARA. These results are likely to support the hypothesis, already presented above, about the common pathogenetic background of both, atopic diseases and ARA on antibiotics, in children. As an alternative explanation of this connection, evidence has been provided by many clinical studies, although not consistently, that antibiotic exposure in early infancy is likely to increase the risk for childhood atopy [13], [17]. This inconsistency in knowledge gained on this issue, might be the consequence of the different behavior of otherwise similar substances, such as in our study the case with fenoksimetil penicillin (cluster 3 ) and ampicillin (cluster 4). The unfavourable drug reaction, in ampicilin risk group (cluster 4), according to our results, might also be supported with the existence of perinatal disorders, implicating immunodeficiency and obstacles in the postnatal immune system development. In numerous studies, conducted to-date, an attention has not been payed to the importance of these very early developmental disturbances. Furthermore, our results also indicate that the occurrence of otitis media in early life (in some reports considered as the complication of influenza virus infection and, as such, the manifestation of the immune system dysfunction) can also be considered as a contributing factor for the early onset of ARA on ampicillin (cluster 4). This risk group, in contrast to the comparative one, for the time of onset (cluster 3), was also prone to the development of severe respiratory disease, although with the onset later in life (at six age), further indicating immunodeficient disorders. When positive family history on ARA is added to this risk group (cluster 4), this all together indicates that a set of inherited and acquired immune system disorders can be important for the occurrence of ARA on this broad-spectrum antibiotic.

Some elements of this pattern, associated with ARA on ampicillin (cluster 4), can be recognized as a part of the cluster describing ARA on cefalosporins (cef\&pen, cluster 1), another broad-spectrum group of antibiotics. These elements, overlapping 
between the two clusters, include perinatal disorders and severe respiratory disease, although here, the severe respiratory disease preceded (and probably contributed to) the onset of ARA (cluster 1). The combined cef\&pen ARA event probably means allergic cross-reaction that may occur between penicillin and cephalosporins of the older generation [6].

Also, it is interesting to observe that two very similar antibiotics, from the common penicillin groups (clusters 2 and 3), have gained much of the similarity in their risk factors patterns.

These results, indicating multiple factors clustered within distinct patterns, each of them specifically associated with a particular risk group (or an antibiotic), are similar to the results of the studies on the association of an early antibiotics use and the occurrence of allergic diseases later in the childhood. According to these studies, a complex cause/outcome model should be formed, in order to make conclusions on this issue, and it is not possible to achieve by analyzing only one, or even a few risk factors [13], [14], [18].

All these factors, extracted from the health records and selected within four clusters, reflect patients` (children`s) clinical and pathophysiological features. We can speculate that the reason why ARA on some other antibiotics, also listed above, have not been presented with a cluster, might be the need for different clinical parameters selection, those ones not recorded in the health records. Alternatively, some other factors could be responsible for ARA, such as, for example, differences in pharmacodynamic mechanisms of drug action. In contribution to this latter explanation, very low ARA rates for macrolide antibiotics have been reported [5].

Results of this study have confirmed some relatively known facts about ARA in children, including the influence of early life infections and antibiotic prescriptions, as well as the predomination of allergic mechanisms underlying ARA, mostly mediated with IgE antibodies. The nature of the association between atopy and ARA in children, also important for understanding childhood allergic diseases, remain to be elucidated in the future. In fact, our results indicate that this association might be important only for early ARA onset (in the first year of life) and for a particular antibiotic used. The main contribution of this paper is in the results clearly showing for the first time that only a cluster of factors can explain ARA, specifically for a particular children group, or an antibiotic.

Results of this study can further be utilized for planning future research on this issue. They can also be useful when preparing recommendations for antibiotics prescription and to guide the standardized health data record. Merely an increase in awareness of physicians on risk factors for ARA in children can be sufficient to change their attitudes towards antibiotics prescription. Computer-based tools would be helpful in many aspects when managing these issues, especially by means of the possibility for systematic data recording and data modeling, suitable for the purpose of prediction and risk factors identification. Also important would be the drug allergy alert and prescription support systems, as well as programs for education promotion [28], [29].

We analyze health records created in a health center in East Croatia to explore new knowledge for adverse reactions and allergy (ARA) on antibiotics in children. 
The broad application of business enterprise hospital information systems amasses large amounts of medical documents, which must be reviewed, observed, and analyzed by human experts. There is need for techniques which enable the qualitybased discovery, the extraction, the integration and the use of hidden knowledge in those documents [30]. Human-Computer Interaction and Knowledge Discovery along with Biomedical Informatics are of increasing importance to effectively gain knowledge, to make sense out of the big data. In the future, we can combine these fields to support the expert end users in learning to interactively analyze information properties thus enabling them to visualize the adverse reactions and allergy (ARA) on antibiotics data[31].

\section{Conclusion}

Biomedical research aims to explore new and meaningful knowledge to provide better healthcare [32]. Adverse reactions and allergy (ARA) from antibiotics in children is an important research issue for the medical domain. In this study, we focused on knowledge discovery for this problem and perform a study based on data mining to predict clusters in the survey data extracted from health records of children in Eastern Croatia.

We used computational techniques and then applied k-means algorithm to the dataset to generate some clusters which have similar features. Our results highlight that some type of antibiotics form different clusters. Medical researchers and pharmaceutical companies can utilize and interpret our results. Despite that our study has some limitations, for example we have small dataset consisting of 42 instances, we hope that we can extend the dataset and apply data mining algorithms on it in the future.

In conclusion, we believe that our study can be good example on data mining for adverse reactions and allergy (ARA) from antibiotics in children.

Acknowledgements. We thank the CD-ARES reviewers for their thorough review and helpful comments to further improve our paper.

\section{References}

[1] Langley, J., Halperin, M., Allergy, S.: to antibiotics in children: perception versus reality. Pediatric Infectious Disease Notes 13(3), 160-163 (2002)

[2] Kramer, M.S., Hutchinson, T.A., Flegel, K.M., Naimark, L., Contardi, R., Leduc, D.G.: Adverse drug reactions in general pediatric outpatients. J. Pediatr. 106, 305-310 (1985)

[3] Menniti-Ippolito, G., Raschetti, R., Da Cas, R., Giaquinto, C., Cantarutti, L.: Active monitoring of adverse drug reactions in children. Italian Paediatric Pharmacosurveillance Multicenter Group. Lancet 355, 1613-1614 (2000)

[4] Cirko-Begovic, A., Vrhovac, B., Bakran, I.: Intensive monitoring of adverse drug reactions in infants and preschool children. Eur. J. Clin. Pharmacol. 36, 63-65 (1989)

[5] Thong, B., Update, Y.-H.: on the management of antibiotic allergy. Allergy Asthma Immunol. Res. 2(2), 77-86 (2010) 
[6] Robinson, J., Hameed, L., Carr, T., Practical, S.: aspects of choosing an antibiotic for patients with a reported allergy to an antibiotic. Clin. Infect. Dis. 35, 26-31 (2002)

[7] Macy, E.T., Poon, K.Y.: Self-reported Antibiotic Allergy Incidence and Prevalence: Age and Sex Effects. The American Journal of Medicine 122(8), 778 (2009)

[8] Krizmanic, V., Majnaric, L.: Adverse reactions and allergy on antibiotics in children. In: SouthCHI 2013, Sloenia (2013)

[9] Kadoyama, K., Kuwahara, A., Yamamori, M., Brown, J.B., Sakaeda, T., Okuno, Y.: Hypersensitivity Reactions to Anticancer Agents:Data Mining of the Public Version of the FDA Adverse Event Reporting System, AERS. Journal of Experimental \& Clinical Cancer Research 30(93), 1-6 (2011)

[10] Tsymbal, A., Pechenizkiy, M., Cunningham, P., Puuronen, S.: Dynamic Integration of Classifiers for tracking concept drift in antibiotic resistance data. Information Fusion 9, 56-68 (2008)

[11] Lamma, E., Manservigi, M., Mello, P., Nanetti, R.F., Storari, S.: The automatic discovery of alarm rules for the validation of microbiological data. In: IDAMAP 2001, London, UK (2001)

[12] Harris, J.M., Mills, P., White, C., Moffat, S., Taylor, A.J.N., Cullinan, P.: Recorded infections and antibiotics in early life: associations with allergy in UK children and their parents. Thorax 62, 631-637 (2007)

[13] Johnson, C.C.J., Ownby, D.R., Alford, S.H., Havstad, S.L., Williams, K., Zoratti, E.M., Peterson, E.L., Joseph, C.L.M.: Antibiotic exposure in early infancy and risk for childhood atopy. J. Allergy Clin. Immunol. 115, 1218-1224 (2005)

[14] Halken, S.: Prevention of allergic disease in childhood: clinical and epidemiological aspects of primary and secondary allergy prevention. Pediatr. Allergy Immunol. 15(suppl. 16), 9-32 (2004)

[15] Headley, J., Northstone, K.: Medication administered to children from o to 7.5 years in the Avon longitudinal study of parents and children (ALSPAC). Eur. J. Clin. Pharmacol. 63(2), 189-195 (2007)

[16] Hawkins, N., Golding, J.: A survey of the administration of drugs to young infants. Br. J. Clin. Pharmacol. 40(1), 79-82 (1995)

[17] Bremner, S.A., Carey, I.M., DeWilde, S., Richards, N., Maier, W.C., Hilton, S.R., Strachan, D.P., Cook, D.G.: Early-life exposure to antibacterials and the subsequent development of hayfever in childhood in the UK: case-control studies using the general practice research database and the doctors' independent network. Clin. Exp. Allerg. 33, $1518-1525$ (2003)

[18] Thomas, M., Custovic, A., Woodcock, A., Morris, J., Simpson, A., Murray, C.S.: Atopic wheezing and early life antibiotic exposure a nested case-control study. Pediatr. Allergy Immunol. 17, 184-188 (2006)

[19] Kozyrskyj, A.L., Ernst, P., Becker, A.B.: Increased risk of childhood asthma from antibiotic use in early life. Chest 131, 1753-1759 (2007)

[20] Han, J., Micheline, K.: Data mining: concepts and techniques. Morgan Kaufmann, San Francisco (2001)

[21] Hall, M., Frank, E., Holmes, G., Pfahringer, B., Reutemann, P., Witten, I.H.: The WEKA data mining software: an update. ACM SIGKDD Explorations Newsletter 11(1), 10-18 (2009)

[22] WEKA: Weka 3: Data Mining Software in Java, http: / /www.cs.waikato.ac.nz/ml/weka (last access: April 18, 2013)

[23] Pham, D.T., Dimov, S.S., Nguyen, C.D.: Selection of k in k-mens clustering. Journal of Mechanical Engineering Science 219, Part C (2005) 
[24] Tiwari, M., Bhai Jha, M.: Enhancing the performance of data mining algorithm in letter image recognition data. International Journal of Computer Applications in Engineering Sciences 223(4946), 217-220 (2012)

[25] Tan, P., Steinbach, M., Kumar, V.: Introduction to data mining. Lecture Notes (2004)

[26] Gomes, E., Fonseca, R., Drug, J.: allergy claims in children: from self-reporting to confirmed diagnosis. Clin. Experiment Allergy 38, 191-198 (2007)

[27] Impicciatore, P., Choonara, I., Clarkson, A., Provasi, D., Pandolfini, C., Bonati, M.: Incidence of adverse drug reaction in paediatric in/out-patients: a systemic review and meta-analysis of prospective studies. Br. J. Clin. Pharmacol. 52, 77-83 (2001)

[28] Madle, G., Kostkova, P., Weinberg, J.: Bugs and drugs on the Web: changes in knowledge of users of a web-based education resource on antibiotic prescribing. Journal of Antimicrobial Chemotherapy 63(1), 221-223 (2009)

[29] Farrell, et al.: Computer games to teach hygiene: an evaluation of the e-Bug junior game. Journal of Antimicrobial Chemotherapy 66(suppl. 5), v39-v44 (2011)

[30] Holzinger, A., Yildirim, P., Geier, M., Simonic, K.-M.: Quality-based knowledge discovery from medical text on the Web Example of computational methods in Web intelligence. In: Pasi, G., Bordogna, G., Jain, L.C. (eds.) Qual. Issues in the Management of Web Information. ISRL, vol. 50, pp. 145-158. Springer, Heidelberg (2013)

[31] Holzinger, A.: On Knowledge Discovery and Interactive Intelligent Visualization of Biomedical Data - Challenges in Human-Computer Interaction \& Biomedical Informatics. In: Conference on e-Business and Telecommunications (ICETE 2012), Rome, Italy, IS9-IS20 (2012)

[32] Holzinger, A., Simonic, K.M., Yildirim, P.: Disease-disease relationships for rheumatic diseases: Web-based biomedical textmining and knowledge discovery to assist medical decision making. In: 36th International Conference on Computer Software and Applications COMPSAC, pp. 573-580. IEEE, Izmir (2012) 